\title{
Comprehensive geriatric assessment in 326 older women with early breast cancer
}

\author{
D O Okonji ${ }^{1}$, R Sinha ${ }^{2}$, I Phillips ${ }^{1}$, D Fatz ${ }^{3}$ and A Ring ${ }^{\star}, 1,2$
}

${ }^{1}$ Breast Unit, Royal Marsden Hospital NHS Foundation Trust, Sutton SM2 5PT, UK; ${ }^{2}$ Brighton and Sussex Medical School, Brighton BN2 5BE, UK and ${ }^{3}$ Research and Development, Brighton and Sussex University Hospitals NHS Trust, Brighton BN2 5BE, UK

Background: One-third of new early breast cancer diagnoses occur in women over 70 years old. However, older women are less likely to receive radical curative treatments. This study prospectively evaluated a cohort of older women using a Comprehensive Geriatric Assessment (CGA) to determine whether fitness explained the apparent under-treatment in this patient group.

Methods: In this multi-centre prospective study, patients aged $\geqslant 70$ years with Stages I-III breast cancer underwent a pretreatment baseline CGA consisting of eight assessment tools. Patients were defined as 'fit' if they had normal score in seven out of eight of the assessment tools. 'High risk' patients were defined as those with grade 3, ER negative, HER2 positive, or node positive breast cancer.

Results: Data on 326 patients were available for full analysis. The median age was 77 years. In all, 182 (56\%) of the total population were defined as high risk, with $49 \%, 61 \%$ and $53 \%$ of those in the $70-74,75-84$ and $\geqslant 85$ years age groups respectively having high risk tumours. A total of 301 patients had sufficient CGA records of whom 131 (44\%) were reported as fit, with $34 \%$, $54 \%$ and $12 \%$ of them in the $70-74,75-84$ and $\geqslant 85$ years age groups respectively. More fit than unfit patients underwent primary breast surgery (100\% vs $91 \%, P=0.0002)$, axillary surgery ( $92 \%$ vs $84 \%, P=0.0340)$, and adjuvant chemotherapy for high-risk disease $(51 \%$ vs $20 \%$, $P=0.0001)$. Rates of adjuvant radiotherapy after wide local excision were not significantly different $(88 \%$ vs $90 \%$ respectively, $P=0.8195$.

Conclusions: In this study, all women $\geqslant 70$ years deemed fit by CGA underwent primary surgery. Nearly $50 \%$ of fit women with high-risk disease did not receive adjuvant chemotherapy suggesting under treatment in this group.

Between 2012 and 2014, 17954 women per year aged 70 years or older were diagnosed with breast cancer, representing approximately $34 \%$ of all new breast cancer diagnoses in the United Kingdom (Cancer Research UK, 2015). The number of women in this age group is increasing rapidly, such that many older people will be diagnosed with cancer over the forthcoming decades (Khaw, 1999). In 2010, the UK National Cancer Equality Initiative concluded that older patients experienced inequalities in access to cancer services and treatment; furthermore, they also had worse outcomes, which were improving at a slower rate than those for younger patients (National Cancer Equality Initiative, 2010).

It is well recognised that older women with breast cancer are less likely to be offered or receive a full diagnostic work-up, surgery or radiotherapy and that such under-treatment is likely to have an impact on prognosis (Bouchardy et al, 2003; Lavelle et al, 2007; Schonberg et al, 2010). Several studies from the US and UK also report low rates of receipt of adjuvant chemotherapy in older women (Enger et al, 2006; Buist et al, 2009; Ring et al, 2013).

However older patients represent a highly heterogeneous population. While the median life expectancy of a 70-year-old woman in the UK is 16 years (Rowan, 2009), there is considerable variability in terms of life-expectancy, co-morbidities, fitness, social situation, cognitive function and desire for treatment. In order to more accurately interpret data describing treatment patterns in older patients, it is vital that the data be put in the context of these variables so as to ascertain whether there is a population of old but

*Correspondence: Dr A Ring; E-mail: alistair.ring@rmh.nhs.uk

Received 15 March 2017; revised 26 May 2017; accepted 13 July 2017; published online 10 August 2017

(C) 2017 Cancer Research UK. All rights reserved 0007-0920/17 
fit women who are being denied treatment on the basis of age alone.

A baseline assessment of the general health of older patients using a Comprehensive Geriatric Assessment (CGA) may help to inform this debate by enabling the identification of where undertreatment may be occurring. This would ultimately facilitate better informed discussions with patients about their fitness to undergo treatment as well as their likely long-term benefits from adjuvant therapy (Gosney, 2005).

The primary objective of The Functional Assessment in Early Breast Cancer in Older Patients (FABIO) study was to characterise a population of women aged 70 years or older with newly diagnosed stages I-III breast cancer by using a CGA to objectively assess their fitness to undergo primary surgery and subsequent adjuvant therapies. The secondary objective was to use these measures to ascertain what proportion of fit older patients are not undergoing radical curative treatments including, surgery, radiotherapy, chemotherapy and anti-human epidermal growth factor receptor 2 (HER2) therapy.

\section{MATERIALS AND METHODS}

This was a multi-centre prospective cohort study. Eligible patients were women aged 70 years or older with a new diagnosis of early (stages I-III) breast cancer, who were willing to provide written informed consent and comply with the study questionnaire and interview schedule. Patients were recruited within 6 weeks of their first diagnosis of early invasive breast cancer. Patients were excluded from the study if they commenced treatment prior to registration into study, lacked mental capacity to consent, and/or their expected prognosis was less than 3 months. Each participant underwent an interview by telephone or in person with a research nurse, to complete a panel of geriatric assessment tools. These were: the 6-Cognitive Impairment Test (6-CIT), American Society of Anesthesiologists (ASA) grade, Eastern Cooperative Oncology Group (ECOG) performance status, Vulnerable Elders Survey (VES-13), Activities of Daily Living (ADL), Instrumental Activities of Daily Living (IADL), G8 score and the Charlson's Co-morbidity index (CCI) (Dripps, 1963; Katz et al, 1963; Lawton and Brody, 1969; Charlson et al, 1987; Saliba et al, 2001; Hodigere and Ramesh, 2006; Upadhyaya et al, 2010; Stokoe et al, 2012 respectively). The interview data were supplemented by further clinical information regarding comorbidities from the patient's general practitioner. Diagnosis details (including tumour type, grade, stage), and treatment received were extracted from the medical records. In the event of recording reduced mental capacity while implementing the 6-CIT test, the patient was considered as a screen failure, and withdrawn from the study. In this situation, notification to the GP, and key-worker was made. Pre-defined thresholds for determination of fitness according to individual geriatric assessment tools were used based on the published literature (Katz et al, 1963; Lawton and Brody, 1969; Saliba et al, 2001; Owusu et al, 2011; Bellera et al, 2012). Scores categorising patients as 'fit' were as follows: ECOG performance status $(P S) \leqslant 1$, ASA grade $\leqslant \mathrm{II}, 6-\mathrm{CIT} \leqslant 7, \mathrm{VES}-13 \leqslant 2, \mathrm{ADL} \geqslant 6, \mathrm{IADL} \geqslant 8, \mathrm{G} 8$ $\geqslant 15$ and $\mathrm{CCL} \leqslant 1$.

Statistical considerations. The primary objective of this study was to characterise the population of women aged 70 or over with newly diagnosed stages I-III breast cancer in terms of objective health assessments. A minimum sample size of 300 was chosen as an achievable target to reach within the timeframes available for conducting the project. The distribution of the CGA scores in this patient population was not known. For the secondary objectives it was estimated that the proportions of fit patients eligible for the radical treatment but not receiving it were $10 \%, 20 \%$ and $70 \%$ for surgery, radiotherapy and chemotherapy respectively. For the purposes of chemotherapy analysis: high-risk patients were defined as those with one or more of the following high-risk features: grade 3 , node positive, oestrogen receptor (ER) negative or HER2 positive (Leonard et al, 2011; Ring et al, 2013).

Analysis was conducted using GraphPad Software 2017. Twotailed $P$-values were calculated using Fisher's exact test, and a $P$-value of $<0.05$ was considered significant.

Follow-up. Patients will be followed up within this cohort for treatment-related toxicity, functional status (by repeat interval measurements of VES-13, ADL and IADL) and long-term (years 1, 2 and 5) survival data.

Patients' management was not influenced by involvement in this study, and the clinicians responsible for the patients as well as the patients themselves were not informed of the results of the assessments. The study was approved by Surrey Research Ethics Committee (11/LO/1672) and by Research and Development departments in participating centres. The study was adopted on to the UK National Cancer Research Network portfolio (study ID 89511).

\section{RESULTS}

Between January 2012 and October 2015, 24 UK specialist breast cancer teams recruited 356 patients into this study. Eight patients withdrew consent and therefore, did not undergo initial assessments; a further 22 patients did not have adequate data points recorded at baseline. Therefore, there were 326 patients available for this analysis. The median age of patients recruited was 77 years. Baseline tumour and treatment characteristics are shown in Table 1.

High-risk patients were defined as those with grade 3, ER negative, HER2 positive, or node-positive breast cancer. Based on this definition: $182(56 \%)$ of the total population were defined as high risk of recurrence, with $49 \%, 61 \%$ and $53 \%$ of the $70-74,75-$ 84 and $\geqslant 85$ years respectively having high-risk tumours.

The eight constituent CGA parameter scores for the population according to pre-defined cut-offs are shown in Table 2.

Fit patients were defined as those did not fail more than one of the eight parameters constituting the CGA. This analysis was possible in 301 patients with sufficient CGA records. On this basis: $131(44 \%)$ of the total study population were reported as 'fit', with $34 \%, 54 \%$ and $12 \%$ of them in the $70-74,75-84$ and $\geqslant 85$ years age groups respectively.

Treatment received according to 'fitness' is shown in Table 3.

\section{DISCUSSION}

In this study, $84 \%$ of participants had $\mathrm{T} 1$ and $\mathrm{T} 2$ early breast cancer and 63\% had lymph node negative disease. These findings are similar to those in a large early breast cancer series from the San Antonio Breast Cancer Database and the US Surveillance, Epidemiology, and End Results (SEER) registry (Diab et al, 2000). However $56 \%$ patients had high-risk disease (as defined by the presence of HER2-positive and/or ER-negative disease or ERpositive grade 3 disease and/or positive axillary lymph nodes), suggesting that a significant proportion of patients in this study had a high risk of recurrence. This is in contrast to the widely held perception that breast cancer in older women is an indolent disease. These patients, assuming that they have a low risk of death from competing causes of mortality and are fit enough for treatment, may derive a benefit from adjuvant radiotherapy and adjuvant systemic therapy. 
Table 1. Patient tumour and treatment characteristics $(N=326)$

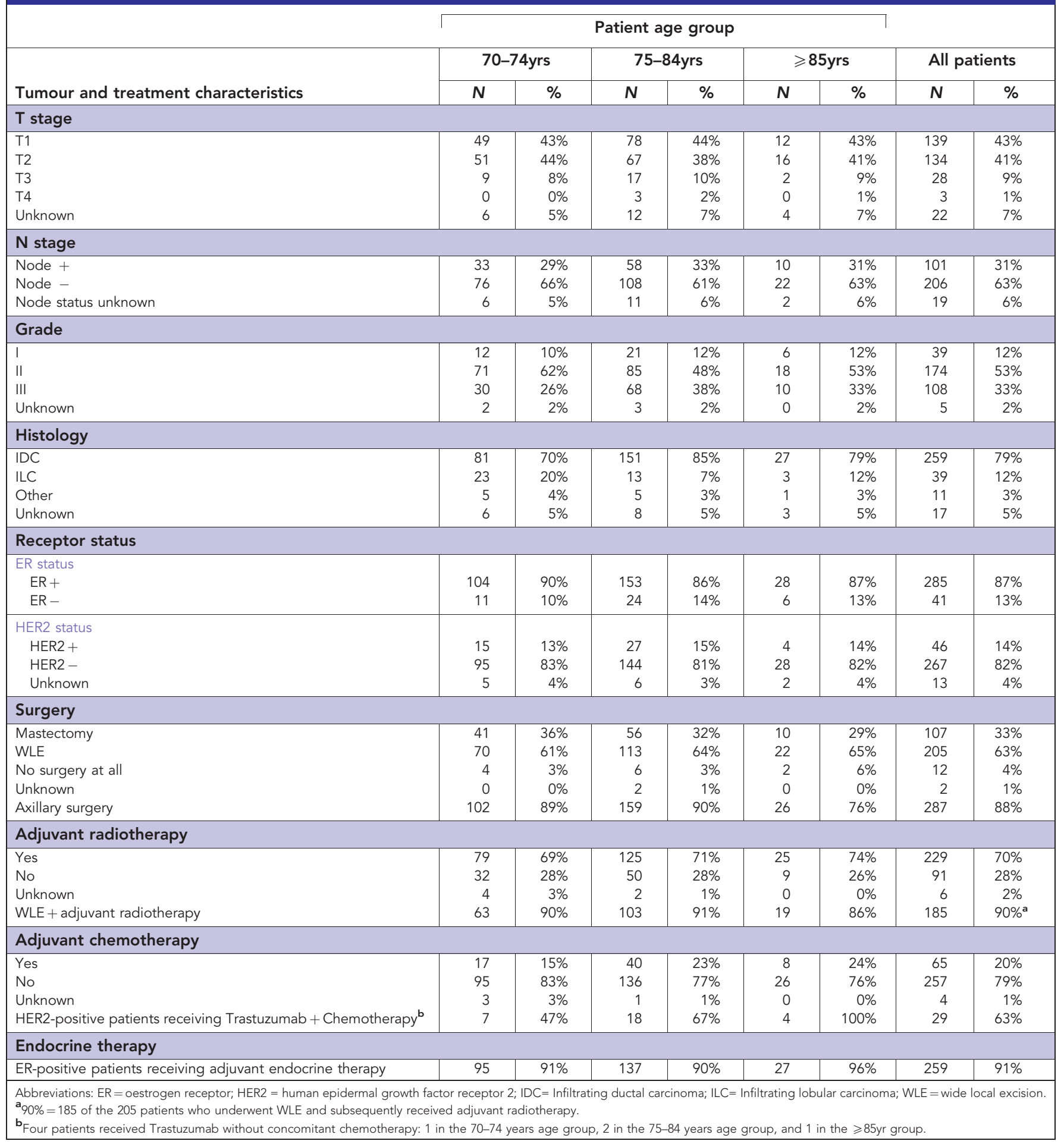

The International Society of Geriatric Oncology (SIOG) and the European Society of Breast cancer Specialists (EUSOMA) both recommend that a baseline geriatric assessment should be undertaken in all patients $\geqslant 70$ years of age prior to consideration of chemotherapy (Pallis et al, 2010; Wildiers et al, 2014). However, there is no consensus on the optimum geriatric assessment (Puts et al, 2012) or on which specific assessment tools should be incorporated into a standardised CGA. Nonetheless, a CGA may help identify patients who may experience functional decline (Hoppe et al, 2013) and also those who are likely to experience toxicity with adjuvant treatment (Freyer et al, 2005; Maione et al, 2005; Hurria et al, 2011; Puts et al, 2012), However there is only limited published evidence regarding the ability of a CGA to reliably predict survival in early breast cancer (Clough-Gorr et al, 2012; Soubeyran et al, 2014). A limitation of interpretation of all of these studies is lack of a uniformly agreed definition of what constitutes a CGA.

What is well-established in the geriatric literature is that any CGA or global assessment of health status needs to incorporate a number of different domains as for the most part these domains 
Table 2. Complete Geriatric Assessment (CGA) parameter scores by age group

\begin{tabular}{|c|c|c|c|c|c|c|c|c|c|}
\hline \multirow[b]{2}{*}{ Complete Geriatric Assessment (CGA) parameters } & & \multicolumn{6}{|c|}{ Patient age group } & \multicolumn{2}{|c|}{ All Patients } \\
\hline & & $N$ & $\%$ & $N$ & $\%$ & $N$ & $\%$ & $N$ & $\%$ \\
\hline$\leqslant 1$ & Fit & 83 & $72 \%$ & 136 & $77 \%$ & 10 & $29 \%$ & 229 & $70 \%$ \\
\hline \multirow[t]{2}{*}{$\geqslant 2$} & Unfit & 29 & $25 \%$ & 36 & $20 \%$ & 23 & $68 \%$ & 88 & $27 \%$ \\
\hline & ECOG PS not recorded & 3 & $3 \%$ & 5 & $3 \%$ & 1 & $3 \%$ & 9 & $3 \%$ \\
\hline$\leqslant 11$ & Fit & 85 & $74 \%$ & 137 & $77 \%$ & 23 & $68 \%$ & 245 & $75 \%$ \\
\hline \multirow{2}{*}{$\geqslant I I I$} & Unfit & 14 & $12 \%$ & 20 & $11 \%$ & 4 & $12 \%$ & 38 & $12 \%$ \\
\hline & ASA not recorded & 16 & $14 \%$ & 20 & $11 \%$ & 7 & $21 \%$ & 43 & $13 \%$ \\
\hline \multicolumn{10}{|l|}{ 6-CIT } \\
\hline \multirow{2}{*}{$\begin{array}{l}\leqslant 7 \\
\geqslant 8\end{array}$} & Fit & 90 & $78 \%$ & 145 & $82 \%$ & 24 & $79 \%$ & 259 & $79 \%$ \\
\hline & Unfit & 22 & $19 \%$ & 30 & $17 \%$ & 10 & $19 \%$ & 62 & $19 \%$ \\
\hline$\geqslant 3$ & VES-13 not recorded & 3 & $3 \%$ & 6 & $3 \%$ & 0 & $0 \%$ & 9 & $3 \%$ \\
\hline \multicolumn{10}{|l|}{ ADL } \\
\hline$\geqslant 6$ & Fit & 99 & $86 \%$ & 149 & $84 \%$ & 31 & $91 \%$ & 279 & $86 \%$ \\
\hline \multirow{2}{*}{$\leqslant 5$} & Unfit & 13 & $11 \%$ & 23 & $13 \%$ & 2 & $6 \%$ & 38 & $12 \%$ \\
\hline & ADL not recorded & 3 & $3 \%$ & 5 & $3 \%$ & 1 & $3 \%$ & 9 & $3 \%$ \\
\hline \multicolumn{10}{|l|}{ IADL } \\
\hline$\geqslant 8$ & Fit & 87 & $76 \%$ & 139 & $79 \%$ & 22 & $65 \%$ & 248 & $76 \%$ \\
\hline \multirow[t]{2}{*}{$\leqslant 7$} & Unfit & 25 & $22 \%$ & 32 & $18 \%$ & 11 & $32 \%$ & 68 & $21 \%$ \\
\hline & IADL not recorded & 3 & $3 \%$ & 6 & $3 \%$ & 1 & $3 \%$ & 10 & $3 \%$ \\
\hline \multicolumn{10}{|l|}{ G8 } \\
\hline \multirow{2}{*}{$\begin{array}{l}\geqslant 15 \\
\leqslant 14\end{array}$} & Fit & 55 & $48 \%$ & 66 & $37 \%$ & 14 & $41 \%$ & 135 & $41 \%$ \\
\hline & Unfit & 56 & $49 \%$ & 105 & $59 \%$ & 19 & $56 \%$ & 180 & $55 \%$ \\
\hline
\end{tabular}

Table 3. Proportion of patients undergoing treatment according to fitness as defined by Complete Geriatric Assessment $(N=301)$

Patient fitness

\begin{tabular}{|c|c|c|c|c|c|}
\hline \multirow[b]{2}{*}{ Treatment } & \multicolumn{2}{|c|}{ Fit } & \multicolumn{2}{|c|}{ Unfit } & \multirow[t]{2}{*}{$\begin{array}{c}\mathrm{X}^{2} \\
P \text {-value }\end{array}$} \\
\hline & $N$ & $\%$ & $\mathbf{N}$ & $\%$ & \\
\hline Breast surgery & $132 /(132)$ & $100 \%$ & $156 /(171)$ & $91 \%$ & 0.0002 \\
\hline Patients undergoing axillary surgery & $122 /(132)$ & $92 \%$ & $144 /(171)$ & $84 \%$ & 0.0340 \\
\hline Adjuvant radiotherapy after WLE & $82 /(93)$ & $88 \%$ & $86 /(96)$ & $90 \%$ & 0.8195 \\
\hline High risk patients receiving chemotherapy & $39 /(76)$ & $51 \%$ & 18/(91) & $20 \%$ & 0.0001 \\
\hline HER2-positive patients receiving Trastuzumab ${ }^{\mathbf{a}}$ & $14 /(21)$ & $67 \%$ & $11 /(19)$ & $58 \%$ & 0.7451 \\
\hline ER-positive receiving endocrine therapy & $102(115)$ & $89 \%$ & $131 /(151)$ & $87 \%$ & 0.7451 \\
\hline
\end{tabular}

can be independent (Pallis et al, 2010). Therefore eight geriatric assessment tools were used in this current study. The specific instruments that constituted the CGA in this analysis were preselected because they have been either established in clinical practice or validated in published studies. Although both the G8 and VES-13 were included, it must be noted that these are normally used as screening tools to help identify elderly patients who may benefit from further geriatric assessments (Decoster et al, 2015) and are not usually part of what would be considered a standard CGA by convention. However, in this study both G8 and VES-13 were utilised not only as screening tools but also as part of the CGA because their constituent items allowed for an objective, reliable and reproducible assessment of nutrition, polypharmacy, psychological status, body weight and functional mobility by the 
research nurses involved in data collection in this study. Of the remaining five tools, ASA and ECOG PS were included because they are commonly used in clinical practice particularly when evaluating fitness in the elderly prior to surgery and the likelihood of tolerating adjuvant chemotherapy respectively. The ADL and IADL tools were included because both have been shown in large studies, either as part of a CGA (Repetto et al, 2002), or alone (van Abbema et al, 2017) to provide more information on not only the baseline functional capacity in the elderly but also the likelihood of functional decline after treatment with chemotherapy. The CCI was also included in the CGA in this study because previously published large trials have shown that multiple comorbidities are associated with poorer survival not only in cancer patients in general (Søgaard et al, 2013) but also in elderly patients with early breast cancer in particular (Patnaik et al, 2011).

The CGA in this study was therefore an aggregate of eight constituent assessment tools. In order to establish a clinically useful output to determine fitness to undergo adjuvant therapies, data derived from the CGA were utilised to try to discriminate a 'fit' from an 'unfit' patient. To the best of the authors' knowledge, this is not an approach that has been used in other published studies. The working definition of 'fit' that was used in this study (i.e. not more than one 'unfit' score in any of the eight assessment tools constituting the CGA) was a pragmatic one to enable an analysis of whether fitness was being used to determine treatment. A key finding from the study was that despite using this fairly stringent definition of fitness, over $40 \%$ of the study population was defined as 'fit'. This is important as patients older than 70 years of age, but who are defined as 'fit' might be expected to have a low risk of death from competing causes compared to those who are unfit but of the same age. Furthermore, it might be hypothesised that they would tolerate treatment.

In this study, all patients who were fit underwent primary breast surgery, compared to only $91 \%$ of the unfit patients $(P=0.0002)$. This would seem appropriate as less fit patients may be well served by primary endocrine therapy rather than primary surgery. Overall though, the rates of primary surgery were higher in this study compared with other analyses (Morgan et al, 2015a). This may reflect selection bias, which might be occurring as sites may be only selecting fitter patients for the study. Furthermore, while a broad range of 24 UK sites were involved, the sites who took part might be those with a particular interest in breast cancer in older patients, and therefore may deploy a different treatment approach to centres which did not take part in the study.

A similar number of unfit and fit patients underwent adjuvant radiotherapy after breast conserving surgery (88\% vs $92 \%$ respectively; $P=0.8195)$. The PRIME II study randomised women aged 65 or over who had undergone breast conserving surgery for ER positive, axillary node negative early breast cancer to receive breast radiotherapy or not (Kunkler et al, 2015). There was a lower risk of ipsilateral breast tumour recurrence in those having radiotherapy $(1.3 \%$ vs $4.1 \%, P=0.0002)$, but the absolute risk was low and there were no differences in regional recurrences, distant metastases, or overall survival. Therefore there is likely to be a population of older patients, with lower risks of recurrence who are less fit where the benefits of adjuvant radiotherapy are marginal. Despite this, in the current study $90 \%$ of patients defined as unfit received radiotherapy, raising the possibility that some of these patients are being over-treated.

In the AChEW study only $30 \%$ of women with high risk early breast cancer aged 70 or older were offered adjuvant chemotherapy, and $17 \%$ went on to receive it (Ring et al, 2013). It was hypothesised that the reason for the low number of patients being offered chemotherapy was that they were not deemed fit enough to benefit from treatment, but fitness was not measured. The current study aimed to answer this question: It showed that more fit patients compared to unfit patients received chemotherapy (51\% vs
$20 \%$ respectively; $P=0.0001$ ), However there were still a large number of fit older patients with high-risk disease who did not receive chemotherapy. The reasons for this are not clear, but may relate to physician perceptions or preferences for treatment on behalf of patients. The large UK National study: 'Bridging the Age Gap in breast cancer' (University of Sheffield, 2017) is a cluster randomised trial that utilises patient and clinician decision-aids to attempt to inform decision-making in this patient group and will continue to address this particular question.

This study has potential limitations. Firstly, the overall number of (whether high risk or not) who received adjuvant chemotherapy was higher than one would expect in either trial or non-trial populations for patients aged of 70 years or older $(20 \%$ overall compared with $8 \%$ for the overall population in the AChEW study). One explanation for this is would be emerging changes in practice resulting in more proactive treatment of older patients with breast cancer (Muss et al, 2005). However, it may also be due to selection bias, with participating sites recruiting generally fitter patients into the study. This would also explain the higher rates of surgery in this elderly patient cohort when compared to other published studies. Secondly, the study also excluded patients with cognitive impairment and thereby may have enriched the potential number of patients characterised as 'fit'. The decision to exclude patients with cognitive impairment was made in order to ensure reliability and consistency of the CGA completion, particularly when assessments were being completed over the telephone. There is increasing evidence, however, to suggest cognitive impairment does influence physician treatment choices and patient preferences in older breast cancer patients who are unfit (Morgan et al, 2014; 2015b). These older patients represent an important sub-group with particular unmet needs, and in which prospective studies such as the Bridging the Age Gap in Breast Cancer (University of Sheffield, 2017) have made particular provision for, with the express aim of providing answers to such questions.

In summary, early breast cancer in women aged 70 is a heterogeneous disease, with many having features of high-risk disease. An objective attempt at determining fitness of patients aged 70 and over using a CGA was achieved in the majority of patients participating in this study. Primary breast surgery was undertaken in most women, whether fit or unfit. In contrast, adjuvant chemotherapy was often not used in most women with breast cancer at high risk of recurrence, even in those deemed fit by a CGA. Therefore, fit women aged over 70 years who undergo primary surgery for early breast cancer, but who do not receive chemotherapy may represent a subgroup of undertreated patients who may benefit from adjuvant treatment. Larger national studies are attempting to better identify these patients in order to increase uptake of adjuvant chemotherapy in this group and thereby improve survival in older patients with early breast cancer.

\section{ACKNOWLEDGEMENTS}

This work was supported by an unrestricted educational grant from Roche Products Limited. Dr Ring and Dr Okonji would also like to acknowledge the support of the Cridlan Fund and the Royal Marsden National Institute for Health: Research Biomedical Research Centre for Cancer. The authors would also like to thank the patients and staff of the recruiting sites: Bronglais General Hospital, Aberystwyth; Castle Hull Hospital, Castle Hill; Charing Cross Hospital, London; County Hospital, Stafford; Cumberland Infirmary, Carlisle; Glan Clwyd Hospital, Rhyl; Great Western Hospital, Swindon; Huddersfield Royal Infirmary, Huddersfield; Kidderminster General Hospital, Kidderminster; North Manchester General Hospital, Manchester; North Middlesex Hospital, London; Northwick Park Hospital, London; Princess of Wales 
Hospital, Bridgend; Queen's Hospital, Burton; Royal Albert Edward Infirmary, Wigan; Royal Bournemouth Hospital, Bournemouth; Royal Glamorgan Hospital, Llantrisant; Royal Sussex County Hospital, Brighton; Russells Hall Hospital, Dudley; Sandwell General Hospital, Lyndon; Solihull Hospital, Solihull; Walsall Manor Hospital, Walsall; Wrexham Maelor Hospital, Wrexham and Ysbyty Gwynedd, Bangor.

\section{CONFLICT OF INTEREST}

The authors declare no conflict of interest.

\section{REFERENCES}

Bellera CA, Rainfray M, Mathoulin-Pélissier S, Mertens C, Delva F, Fonck M, Soubeyran PL (2012) Screening older cancer patients: first evaluation of the G-8 geriatric screening tool. Ann Oncol 23(8): 2166-2172.

Bouchardy C, Rapiti E, Fioretta G, Laissue P, Neyroud-Caspar I, Schäfer P, Kurtz J, Sappino AP, Vlastos G (2003) Under-treatment strongly decreases prognosis of breast cancer in elderly women. J Clin Oncol 21(19): 3580-3587.

Buist DSM, Chubak J, Prout M, Yood MU, Bosco JL, Thwin SS, Gold HT, Owusu C, Field TS, Quinn VP, Wei F, Silliman RA (2009) Referral, receipt, and completion of chemotherapy in patients with early-stage breast cancer older than 65 years and at high risk of breast cancer recurrence. J Clin Oncol 27(27): 4508-4514.

Cancer Research UK (2015) Breast cancer incidence (invasive) statistics. CRUK: London, UK. Available at: http://www.cancerresearchuk.org/ health-professional/cancer-statistics/statistics-by-cancer-type/breastcancer/incidence-invasive (accessed 11 December 2016).

Charlson ME, Pompei P, Ales K, Mackenzie CR (1987) A new method of classifying prognostic co-morbidity in longitudinal studies: development and validation. J Chronic Dis 40(5): 373-383.

Clough-Gorr KM, Thwin SS, Stuck AE, Silliman RA (2012) Examining fiveand ten-year survival in older women with breast cancer using cancerspecific geriatric assessment. Eur J Cancer 48(6): 805-812.

Decoster L, Van Puyvelde K, Mohile S, Wedding U, Basso U, Colloca G, Rostoft S, Overcash J, Wildiers H, Steer C, Kimmick G, Kanesvaran R, Luciani A, Terret C, Hurria A, Kenis C, Audisio R, Extermann M (2015) Screening tools for multidimensional health problems warranting a geriatric assessment in older cancer patients: an update on SIOG recommendations. Ann Oncol 26(2): 288-300.

Diab SG, Elledge RM, Clark GM (2000) Tumor characteristics and clinical outcome of elderly women with breast cancer. J Natl Cancer Inst 92(7): 550-556.

Dripps RD (1963) New classification of physical status. Anesthesiology 24: 111.

Enger SM, Thwin SS, Buist DS, Field T, Frost F, Geiger AM, Lash TL, Prout M, Yood MU, Wei F, Silliman RA (2006) Breast cancer treatment of older women in integrated health care settings. J Clin Oncol 24(27): 4377-4383.

Freyer G, Geay JF, Touzet S, Provencal J, Weber B, Jacquin JP, Ganem G, Tubiana-Mathieu N, Gisserot O, Pujade-Lauraine E (2005) Comprehensive geriatric assessment predicts tolerance to chemotherapy and survival in elderly patients with advanced ovarian carcinoma: a GINECO study. Ann Oncol 16: 1795-1800.

Gosney M (2005) Clinical assessment of elderly people with cancer. Lancet Oncol 6(10): 7907.

Hodigere SJ, Ramesh TB (2006) Risk assessment for cancer surgery in elderly patients. Clin Interv Aging 1(3): 221-227.

Hoppe S, Rainfray M, Fonck M, Hoppenreys L, Blanc JF, Ceccaldi J, Mertens C, Blanc-Bisson C, Imbert Y, Cany L, Vogt L, Dauba J, Houédé N, Bellera CA, Floquet A, Fabry MN, Ravaud A, Chakiba C, Mathoulin-Pélissier S, Soubeyran P (2013) Functional decline in older patients with cancer receiving first-line chemotherapy. J Clin Oncol 31(31): 3877-3882.

Hurria A, Togawa K, Mohile SG, Owusu C, Klepin HD, Gross CP, Lichtman SM, Gajra A, Bhatia S, Katheria V, Klapper S, Hansen K, Ramani R, Lachs M, Wong FL, Tew WP (2011) Predicting chemotherapy toxicity in older adults with cancer: a prospective multicenter study. J Clin Oncol 29(25): 3457-3465.
Katz S, Ford AB, Moskowitz RW, Jackson BA, Jaffe MW (1963) Studies of illness in the aged, the index of ADL: a standardized measure of biological and psychosocial function. J Am Med Assoc 185: 914-919.

Khaw KT (1999) How many, how old, how soon? Br Med J 319: 1350-1352. Kunkler IH, Williams LJ, Jack WJ, Cameron DA, Dixon JM. PRIME II investigators (2015) Breast-conserving surgery with or without irradiation in women aged 65 years or older with early breast cancer (PRIME II): a randomised controlled trial. Lancet Oncol 16(3): 266-273.

Lavelle K, Todd C, Moran A, Howell A, Bundred N, Campbell M (2007) Non-standard management of breast cancer increases with age in the UK: a population based cohort of women aged 65 years. Br J Cancer 96(8): 1197-1203.

Lawton MP, Brody EM (1969) Assessment of older people: Self maintaining and instrumental activities of daily living. Gerontologist 9(3): 179-186.

Leonard R, Ballinger R, Cameron D, Ellis P, Fallowfield L, Gosney M, Johnson L, Kilburn LS, Makris A, Mansi J, Reed M, Ring A, Robinson A, Simmonds P, Thomas G, Bliss JM (2011) Adjuvant chemotherapy in older women (ACTION) Study-what did we learn from the pilot phase? Br J Cancer 105: 1260-1266.

Maione P, Perrone F, Gallo C, Manzione L, Piantedosi F, Barbera S, Cigolari S, Rosetti F, Piazza E, Robbiati SF, Bertetto O, Novello S, Migliorino MR, Favaretto A, Spatafora M, Ferraù F, Frontini L, Bearz A, Repetto L, Gridelli C, Barletta E, Barzelloni ML, Iaffaioli RV, De Maio E, Di Maio M, De Feo G, Sigoriello G, Chiodini P, Cioffi A, Guardasole V, Angelini V, Rossi A, Bilancia D, Germano D, Lamberti A, Pontillo V, Brancaccio L, Renda F, Romano F, Esani G, Gambaro A, Vinante O, Azzarello G, Clerici M, Bollina R, Belloni P, Sannicolò M, Ciuffreda L, Parello G, Cabiddu M, Sacco C, Sibau A, Porcile G, Castiglione F, Ostellino O, Monfardini S, Stefani M, Scagliotti G, Selvaggi G, De Marinis F, Martelli O, Gasparini G, Morabito A, Gattuso D, Colucci G, Galetta D, Giotta F, Gebbia V, Borsellino N, Testa A, Malaponte E, Capuano MA, Angiolillo M, Sollitto F, Tirelli U, Spazzapan S, Adamo V, Altavilla G, Scimone A, Hopps MR, Tartamella F, Ianniello GP, Tinessa V, Failla G, Bordonaro R, Gebbia N, Valerio MR, D'Aprile M, Veltri E, Tonato M, Darwish S, Romito S, Carrozza F, Barni S, Ardizzoia A, Corradini GM, Pavia G, Belli M, Colantuoni G, Galligioni E, Caffo O, Labianca R, Quadri A, Cortesi E, D’Auria G, Fava S, Calcagno A, Luporini G, Locatelli MC, Di Costanzo F, Gasperoni S, Isa L, Candido P, Gaion F, Palazzolo G, Nettis G, Annamaria A, Rinaldi M, Lopez M, Felletti R, Di Negro GB, Rossi N, Calandriello A, Maiorino L, Mattioli R, Celano A, Schiavon S, Illiano A, Raucci CA, Caruso M, Foa P, Tonini G, Curcio C, Cazzaniga M (2005) Pretreatment quality of life and functional status assessment significantly predict survival of elderly patients with advanced non-small-cell lung cancer receiving chemotherapy: a prognostic analysis of the multicenter Italian lung cancer in the elderly study. J Clin Oncol 23(28): 6865-6872.

Morgan J, Richards P, Ward S, Francis M, Lawrence G, Collins K, Reed M, Wyld L (2015a) Case-mix analysis and variation in rates of non-surgical treatment of older women with operable breast cancer. Br J Surg 102(9): 1056-1063.

Morgan JL, Collins K, Reed MW, Mamdani J, Cousins S, Ingram S, Wyld L (2014) Bridging the age gap in breast cancer interim analysis of the impact of comorbidity, dementia and frailty on rates of surgery in older women. Eur J Surg Oncol 40(11): S39-S40.

Morgan JL, Collins K, Robinson TG, Cheung KL, Audisio R, Reed MW, Wyld L (2015b) Healthcare professionals' preferences for surgery or primary endocrine therapy to treat older women with operable breast cancer. Eur J Surg Oncol 41(9): 1234-1242.

Muss HB, Woolf S, Berry D, Cirrincione C, Weiss RB, Budman D, Wood WC, Henderson IC, Hudis C, Winer E, Cohen H, Wheeler J, Norton L. Cancer and Leukemia Group B (2005) Adjuvant chemotherapy in older and younger women with lymph node-positive breast cancer. J Am Med Assoc 293(9): 1073-1081.

National Cancer Equality Initiative (2010) Reducing cancer inequality: evidence, progress and making it happen: report by the National Cancer Equality Initiative, Department of Health. Central Office of Information (COI): London, UK, pp 1-99.

Owusu C, Koroukian S, Schluchter M, Bakakib P, Bergera NA (2011) Screening older cancer patients for a comprehensive geriatric assessment: a comparison of three screening instruments. J Geriatr Oncol 2(2): 121-129.

Pallis AG, Fortpied C, Wedding U, Van Nes MC, Penninckx B, Ring A, Lacombe D, Monfardini S, Scalliet P, Wildiers H (2010) EORTC elderly 
task force position paper: approach to the older cancer patient. Eur $J$ Cancer 46(9): 1502-1513.

Pallis AG, Wedding U, Lacombe D, Soubeyran P, Wildiers H (2010) Questionnaires and instruments for a multidimensional assessment of the older cancer patient: what clinicians need to know? Eur J Cancer 46(6): 1019-1025.

Patnaik JL, Byers T, Diguiseppi C, Denberg TD, Dabelea D (2011) The influence of comorbidities on overall survival among older women diagnosed with breast cancer. J Natl Cancer Inst 103(14): 1101-1111.

Puts MT, Hardt J, Monette J, Girre V, Springall E, Alibhai SM (2012) Use of geriatric assessment for older adults in the oncology setting: a systematic review. J Natl Cancer Inst 104(15): 1134-1164.

Repetto L, Fratino L, Audisio RA, Venturino A, Gianni W, Vercelli M, Parodi S, Dal Lago D, Gioia F, Monfardini S, Aapro MS, Serraino D, Zagonel V (2002) Comprehensive geriatric assessment adds information to Eastern Cooperative Oncology Group performance status in elderly cancer patients: an Italian Group for Geriatric Oncology Study. J Clin Oncol 20(2): 494-502.

Ring A, Harder H, Ballinger R, Langridge C, Fallowfield L (2013) Adjuvant chemotherapy in older women with breast cancer (AChEW): identifying perceptions and putative barriers in decision-making. Ann Oncol 24(5): 1211-1219.

Rowan S (2009) National Population Projections, 2008-based reference volume: Series PP2: No. 27. Office for National Statistics (ONS): London, UK, pp 41-43.

Schonberg MA, Marcantonio ER, Li D, Silliman RA, Ngo L, McArthy EP (2010) Breast cancer among the oldest old: tumor characteristics, treatment choices and survival. J Clin Oncol 28(12): 2038-2045.

Saliba D, Elliott M, Rubenstein LZ, Solomon RT, Young CJ, Kamberg RN, Carol R, MacLean CH, Shekelle PG, Sloss EM, Wenger NS (2001) The Vulnerable Elders Survey: a tool for identifying vulnerable older people in the community. J Am Geriatr Soc 49(12): 1691-1699.

Søgaard M, Thomsen RW, Bossen KS, Sørensen HT, Nørgaard M (2013) The impact of comorbidity on cancer survival: a review. Clin Epidemiol 5(Suppl 1): 3-29.
Soubeyran P, Bellera C, Goyard J, Heitz D, Curé H, Rousselot H, Albrand G, Servent V, Jean OS, van Praagh I, Kurtz JE, Périn S, Verhaeghe JL, Terret C, Desauw C, Girre V, Mertens C, Mathoulin-Pélissier S, Rainfray M (2014) Screening for vulnerability in older cancer patients: the ONCODAGE Prospective Multicenter Cohort Study. PLoS One 9(12): $1-20$.

Stokoe JM, Pearce J, Sinha R, Ring A (2012) G8 and VES-13 scores predict chemotherapy toxicity in older patients with cancer. J Geriatr Oncol 3: S81 (abstract P95).

University of Sheffield (2017) Bridging the age gap in breast cancer. Available at: https://www.sheffield.ac.uk/oncology-metabolism/research/ surgicaloncology/research/agegap (accessed 25 May 2017).

Upadhyaya AK, Rajagopal M, Gale TM (2010) The Six Item Cognitive Impairment Test (6-CIT) as a screening test for dementia: comparison with Mini-Mental State Examination (MMSE). Curr Aging Sci 3(2): 138-142.

van Abbema D, van Vuuren A, van den Berkmortel F, van den Akker M, Deckx L, Buntinx F, van Kampen R, Lambooij E, de Boer M, de Vos-Geelen J, Tjan-Heijnen VC (2017) Functional status decline in older patients with breast and colorectal cancer after cancer treatment: a prospective cohort study. J Geriatr Oncol 8(3): 176-184.

Wildiers H, Heeren P, Puts M, Topinkova E, Janssen-Heijnen ML, Extermann M, Falandry C, Artz A, Brain E, Colloca G, Flamaing J, Karnakis T, Kenis C, Audisio RA, Mohile S, Repetto L, Van Leeuwen B, Milisen K, Hurria A (2014) International Society of Geriatric Oncology consensus on geriatric assessment in older patients with cancer. J Clin Oncol 32(24): 2595-2603.

This work is published under the standard license to publish agreement. After 12 months the work will become freely available and the license terms will switch to a Creative Commons AttributionNonCommercial-Share Alike 4.0 Unported License. 